\title{
Beiträge zur Kenntnis der Blattentwicklung einiger phanerogamer Pflanzen.
}

\author{
Von Friedr. Herrig.
}

(Mit 26 Abbildungen im Text.)

\section{Einleitung.}

Während bei den Kryptogamen durch eine Reihe eingehender Arbeiten eine Analyse des Wachstums und der Zellteilungsvorgänge in der SproBspitze und in den Blattanlagen gelungen ist, haben die bei den phanerogamen Pflanzen angestellten Untersuchungen bislang nicht zu dem gleichen Erfolge geführt. In ihren zu Anfang der $70 \mathrm{er}$ Jahre veröffentlichten Arbeiten über die Entwicklung der Stammscheitel der Phanerogamen gehen v. Hanstein, Russow, Schmitz und andere in der Hauptsache nur auf die Sonderung des Urmeristems in Dermatogen, Periblem und Plerom und die Differenzierung des letzteren in Grund- und Leitbündelgewebe ein.

Schmitz gibt allerdings in seiner Habilitationsschrift: „Beobachtungen über die Entwicklung der Sproßspitze der Phanerogamen" eine etwas genauere Untersuchung über die Entstehung der seitlichen Ausgliederungen mehrerer Dicotylen aus den verschiedenen Zellagen des Urmeristems, doch konnte er mit den damaligen Hilfsmitteln die einzelnen Teilungsschritte bei Anlage der jugendlichen Blätter und Sprosse nicht verfolgen. Immerhin sah er bereits, daB das Mesophyll des Blattes samt den in ihm liegenden Blattbündeln aus dem Periblem allein hervorgeht.

Mitte der 80 er Jahre glaubte man bei den Phanerogamen ein dem der Kryptogamen entsprechendes Scheitelzellwachstum gefunden zu haben. Ich nenne die Arbeiten von Dingler: "Scheitelwachstum der Gymnospermen" und Korschelt: „Zur Frage über das Scheitelwachstum bei Phanerogamen“, in denen die Ansicht vertreten wird, daB es sich bei den Phanerogamen um ein Wachstum mit einer Scheitelzelle handle. Dieser Ansicht trat Percy Groom, ein Schüler Strasburger's, in seiner 1885 erschienenen Mitteilung: „Über Vegetationspunkte der Phanerogamen“ entgegen, aber zu einer überzeugenden Lösung des Problems kam er nicht.

Erst die neuere Zeit brachte wieder einzelne Untersuchungen auf diesem Gebiet, so diejenigen Haberlandts über die Sproßentwicklung bei Ceratophyllum demersum, in denen ausgeführt wird, daß im Sproßscheitel dieser Pflanze Dermatogen, Periblem und Plerom mit eigenen Initialen wachsen, und zwar das Plerom mit einer dreischneidigen Scheitelzelle, während die Zahl der Periblem- und Dermatogenzellen durch anti- und perikline Teilungen der Scheitelinitialen sich vermehrt.

Die letzten Arbeiten, die auf unser Thema Bezug haben, rühren von Lé on Flot her. Sie führen den Titel: „, Recherches sur la naissance des feuilles et sur l'origine foliaire de la tige." Eine genaue Analyse der Wachstumsweise der Sprobscheitel und der jungen Blattanlagen führt der Verfasser nicht durch. 
Die Anregung zu den Untersuchungen, über die in dieser Arbeit berichtet wird, erhielt ich durch Herrn Geheimrat Haberlandt, in dessen Institut meine Arbeit entstand, und durch Herrn Professor B aur, für dessen Theorie der Periklinalchimären eine genauere Kenntnis der Blattentwicklung von größter Bedeutung ist.

Ich habe an einer Reihe von Objekten die Frage zu beantworten versucht. wie ihre Sproßscheitel aufgebaut sind, wie sie wachsen, aus welchen Elementen, und wie sich ihre Blattanlagen entwickeln.

Naturgemäß begann ich mit einfachsten Objekten. Um einen Überblick zu bekommen, welche Pflanzenscheitel geeignet seien, welche nicht, prüfte ich eine Anzahl Vegetationsspitzen auf ihre Brauchbarkeit für die beabsichtigte Untersuchung. Es waren dies folgende:

1. Elodea canadensis. (Rich.) Casp.

2. Elodea densa. (Planck) Casp.

3. Hippurus vulgaris. L.

4. Origanum vulgare. L.

5. Glechoma hederacea. L.

6. Salvia glutinosa. L.

7. Galium rubioides. L.

8. Ligustrum vulgare. L.

9. Honckenya peploides. L.

Von diesen neun Objekten, die sämtlich entweder quirlige oder dekussierte Blattstellung besitzen, erwiesen sich die beiden Elodea-Arten, Hippuris, Galium und Honckenya als für die weitere Untersuchung geeignet, während die anderen teils wegen der geringen Größe der meristematischen Zellen, teils wegen der nicht auffälligen Grenzen der verschiedenen Histogene (Dermatogen, Periblem und Plerom) wenig Aussicht auf Erfolg versprachen.

$\mathrm{Zu}$ den einfacheren Objekten gehören Elodea und Hippuris, zu den schwieriger zu untersuchenden dagegen Galium und Honckenya. Alle haben den Vorzug, durch ihre wirtelige oder dekussierte Blattstellung die Möglichkeit medianer Schnittführung zu erleichtern.

\section{Methodisches.}

Von dem untersuchten Material stammen Elodea und Galium aus dem Universitätsgarten. Hippuris ist in der Berliner Umgegend häufig und war daher leicht zu beschaffen. Honckenya fiel mir bei einem Besuch der Ostseeküste durch seine dicken fleischigen, ungestielten Blätter und das genaue Einhalten der dekussierten Blattstellung auf.

Alle Objekte fixierte ich stets an Ort und Stelle, um einem Schrumpfen des Gewebes vorzubeugen. Die Scheitel wurden sorgfältig herauspräpariert und, soweit wie möglich, von den darüber zusammenschließenden Blättern befreit. Damit die Fixierungsflüssigkeit nicht infolge des Anhaftens von Luftblasen ungleichmäßig einwirkt, ist ein Auspumpen der Luft mit einer Wasserstrahlluftpumpe zweckmäßig.

Die zuerst als Fixierungsflüssigkeit benutzte Juel'sche Lösung erwies sich zufolge der durch das Zinkchlorid verursachten Quellung 
der Wände als ungünstig. Bessere Resultate ergaben Carnoy'sche Lösung in der Zusammensetzung: 6 Teile Alkohol abs., 3 Teile Chloroform, 1 Teil Eisessig und Chromessigsäure von der Zusammensetzung: Chromsäure $10 \mathrm{~g}$, Essigsäure $15 \mathrm{ccm}$, Wasser $1000 \mathrm{ccm}$.

Die Einbettung der Objekte in Paraffin geschah in der üblichen Weise durch Überführung mittels Alkohol-Chloroform.

Die Schnitte wurden auf einem Minot'schen Mikrotom, Modell Leitz, hergestellt, die Schnittdicke betrug $5 \mu$. Geschnitten wurden von jedem Objekt etwa 150 Scheitel, um eine möglichst große Zahl verschiedener Entwicklungsstadien zu erhalten.

Gefärbt wurde mit Hämatoxylin-Eisenallaun und mit EosinAlkohol oder Eosin-Nelkenöl gegengefärbt.

Die Zeichnungen sind mit dem Zeichenprisma aufgenommen unter Verwendung der homogenen Immersion ${ }^{1} / 12$, Apert. 1,30 und der Okulare 1 und 3 von Leitz: Die Vergrößerung war eine 500- und 800 fache.

\section{Eigene Untersuchungen.}

\section{Elodea canadensis und Elodea densa.}

Die Untersuchung ergab, daß an den Scheiteln von Elodea canadensis und Elodea densa, abgesehen von den etwas größeren Zellen und den vielzähligeren Blattwirteln von Elodea densa, keine Unterschiede im anatomischen Bau auftreten.

Untersucht wurde Elodea canadensis schon von Kny (1878) und von Haberlandt (1880). Kny gibt an, daß die Grenze zwischen Plerom und Periblem keine scharfe sei, wörtlich sagt er: ,Doch ist es mir aus der Stellung der gewöhnlich schon dicht unterhalb des Scheitels sich differenzierenden Luftkanäle und aus den beobachteten Zellteilungen zweifellos geworden, daß auch hier eine scharfe Sonderung zwischen Plerom und Periblem nicht besteht." Von Haberlandt wurde auf die Entstehung der Blätter hingewiesen, deren Mittelnerv nach ihm auf eine einzige Peribleminitiale zurückzuführen ist, welche entweder eine einfache Zellreihe auszubilden scheint, oder sich durch alternierend rechts und links gebildete Wände etwa nach Art einer zweischneidigen Scheitelzelle teilt.

\section{Der Sprobscheitel.}

Nach meinen Beobachtungen zeigen die Sproßscheitel beider ElodeaArten drei deutlich voneinander geschiedene Histogene, Dermatogen, Periblem und Plerom, deren Grenzen sich ein Stück weit vom Scheitel nach rückwärts verfolgen lassen. 
Während das Dermatogen anscheinend von einer Gruppe scheitelständiger Initialen ausgeht, findet man für das Periblem und das Plerom stets je eine Initialzelle.

Besonders deutlich ist die einzellige Spitze - die Scheitelzelle des Pleroms, von welcher aus die Abgliederung der Zellen der Plerom-

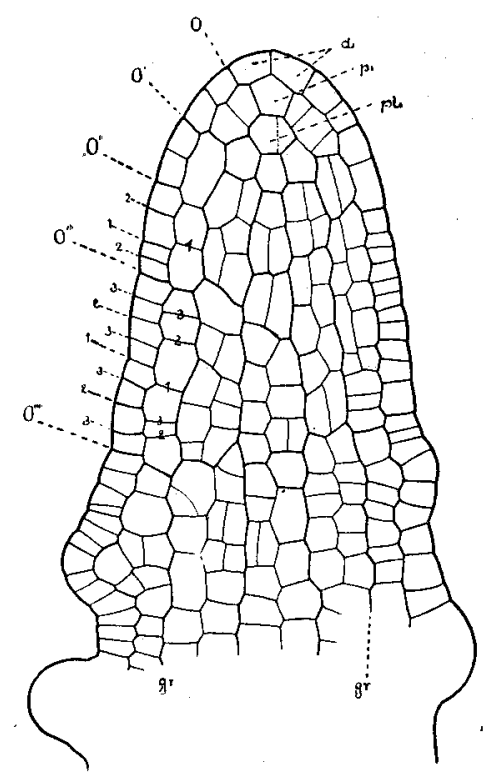

Fig. $1^{1}$ ). Längsschnitt durch einen Scheitel von Elodea canadensis. $d i$ Dermatogeninitiale, $p i$ Peribleminitiale, pli Plerominitiale. Die mit $o^{\prime}, o^{\prime \prime}, o^{\prime \prime \prime}, o^{\prime \prime \prime \prime}$ bezeichneten Wände im Dermatogen entsprechen den Grenzen primärer Dermatogenzellen. Mit $I$ sind die ersten Teilungswände innerhalb dieser Zellen bezeichnet, mit 2 die zweiten, mit 3 die dritten. Das gleiche gilt für die Bezeichnung der Periblemzellwände. Die ursprünglichen Zellgrenzen sind stärker ausgezogen. Vergr. ca. 200. säule ziemlich regelmäßig stattfindet, so da $B$ die Tochterzellen und ihre Teilungsprodukte an einem meiner Präparate in fast segmentaler Anordnung zu erkennen waren.

Fig. 1 stellt den medianen Längsschnitt durch einen Scheitel von Elodea canadensis dar, der zur näheren Erläuterung dieser Verhältnisse dienen mag. Die mutmaßlichen Initialen der drei Schichten sind mit $d i=$ Dermatogeninitiale, $p i=$ Peribleminitiale und $p l i=$ Plerominitiale bezeichnet. Die Entstehungsfolge der älteren Wände ist zwar nicht mit absoluter Gewißheit, aber doch mit einiger Sicherheit zu verfolgen.

In der Zeichnung habe ich versucht, gewisse, aus einer Zelle hervorgegangene Zellkomplexe durch Linien verschiedener Stärke hervorzuheben. In der Höhe der Scheitelkuppe ist man sehr oft nicht im Zweifel, welche Zellen zu einem Komplex zusammenzufassen sind, dagegen hört weiter rückwärts die Möglichkeit einer Abgrenzung der Deszendenten einer Zelle von denen einer anderen auf.

Versuchen wir uns zunächst einen Begriff von der Wachstumsweise des Dermatogens zu machen. Die genauere Beobachtung der äußeren Begrenzungslinie des Dermatogens zeigt, daß gewisse Knickstellen schärfer hervortreten als andere, und daß an sie die dickeren antiklinen Wände ansetzen. Geeignet zu einer Analyse der Wachstums-

1) Die Buchstaben $g r$ bezeichnen in allen Fällen die Grenze des Pleroms und des Periblems, $b l$ eine Blattanlage. 
vorgänge ist das Dermatogen der linken Seite der Fig. 1. Alle Zellen, die zwischen zwei mit $o$ bezeichneten Linien liegen, stammen von je einer Mutterzelle ab. Die Teilungsweise der Zellen ist derart, daß zunächst jede von den Dermatogeninitialen ábstammende Zelle antiklin halbiert wird (zwischen $o^{\prime}$ und $o^{\prime \prime}$ ), ihre Tochterzellen werden wieder halbiert (siehe die Zellen zwischen $o^{\prime \prime}$ und $o^{\prime \prime \prime}$ ) usw. Aus einer Mutterzelle werden also zuerst zwei, dann vier und dann acht Zellen usw. Einzelne Abweichungen kommen vor. Wie viel mal die ursprünglichen Mutterzellen und ihre Deszendenten sich teilen, läßt sich nicht feststellen.

Je weiter die aus einer Mutterzelle hervorgegangenen Areale (zwischen $o^{\prime \prime \prime}$ und $o^{\prime \prime \prime \prime}$ ) vom Scheitel fortgerückt erscheinen, aus desto mehr Zellen bestehen sie (vgl. Fig. 1 links). Die beiden dem Scheitel nächstliegenden Areale sind zweizellig, das folgende vierzellig und das vierte achtzellig (Fig. 1 links). Auf der anderen Seite der Fig. 1 ist der Schnitt streckenweise auf der Grenze zwischen zwei zickzackförmig ineinander greifenden Dermatogenzelllängsreihen entlang gegangen. Die Zahl der getroffenen Zellen ist also hoch und die Zellen selbst erscheinen verhältnismäßig klein. $\mathrm{Zu}$ einer Analyse ist deshalb diese Seite nicht geeignet.

Die. aus der Peribleminitiale gebildeten primären Periblemzellen teilen sich nicht ganz so regelmäßig antiklin. Hier und da treten auch perikline Wände auf. Bei rein antikliner Teilung findet zuerst Halbierung, dann Halbierung der Hälften statt usw. wie bei der Bildung der Dermatogenzellen. Die Entstehungsfolge der Periblemwände ist auf der linken Seite der Fig. 1 mit Zahlen bezeichnet. Auf der rechten Seite von Fig. 1 sind einige primäre Periblemzellen periklin geteilt. Das Periblem ist eine Strecke weit zweischichtig, ohne jedoch Zweifel über die Grenzen von Periblem und Plerom entstehen zu lassen.

\section{Blatt und Seitenachse.}

Fig. 2 zeigt einen fast medianen Scheitellängsschnitt von Elodea densa, welcher über die Entstehung und den Aufbau von Blatt und Seitensproß wichtige Aufschlüsse gibt.

In einiger Entfernung vom Scheitel sieht man auf der rechten Seite des Schnittes eine Reihe junger Blattanlagen verschiedenen Alters, die mit den Anlagen der linken Seite deutlich alternieren. Es gehören daher die Blattanlagen der rechten Seite etwa dem ersten, dritten, fünften usw. Quirl an, die der linken entsprechend dem zweiten, vierten und sechsten usw. Ihre Entwicklung haben diese Blattanlagen unzweifelhaft aus dem Dermatogen und dem Periblem allein genommen. Auf der 
gleichen Seite befindet sich etwas tiefer am Stamm die Anlage eines jungen Seitensprosses, in dessen zentrale Partie sich die Zellen des Pleroms des Muttersprosses hineinschieben. Darüber hinweg läuft das

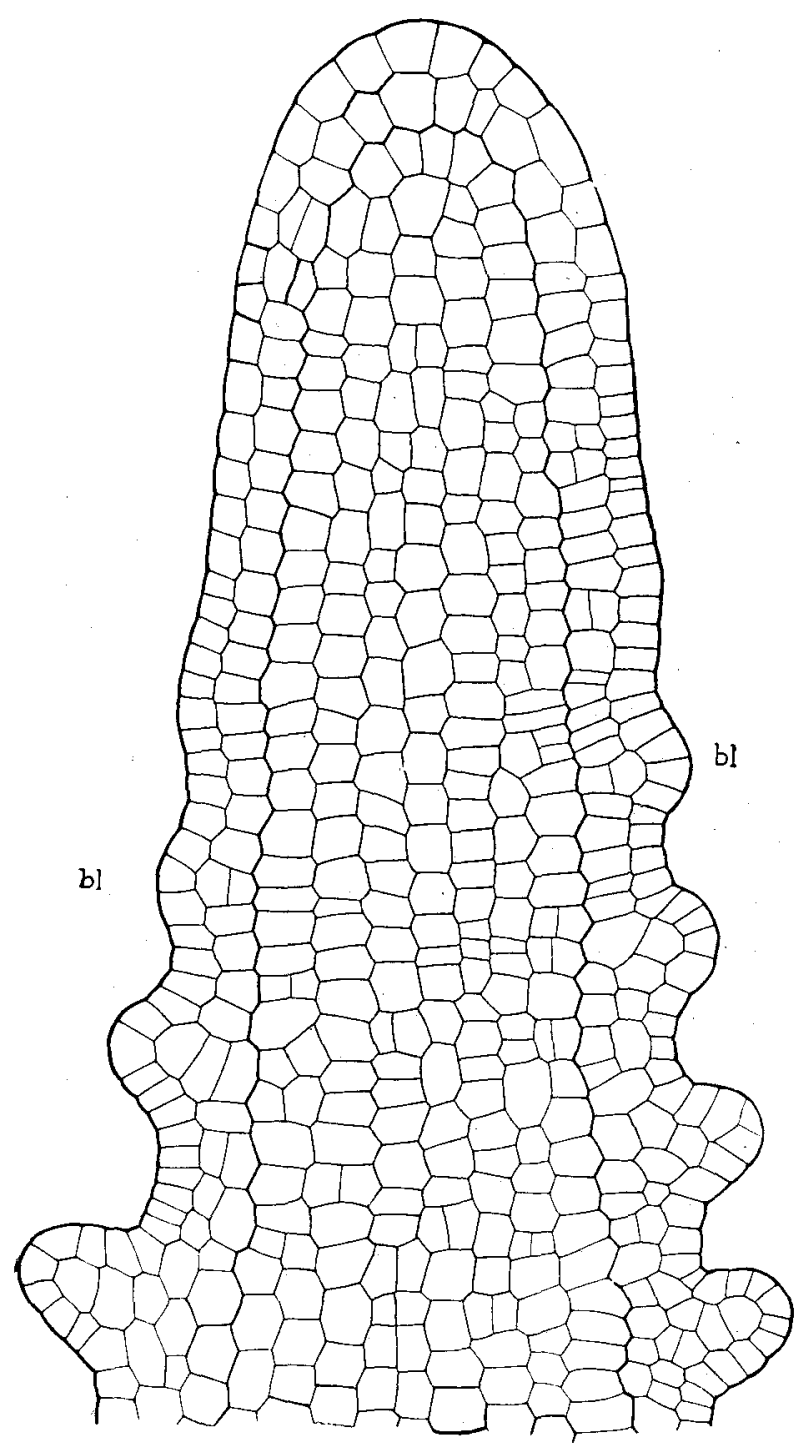

Fig. 2. Längsschnitt durch einen Scheitel von Elodea densa. Vergr. ca. 260. einschichtige Periblem (Fig. 3).

Das Plerom wirkt also nur beim Aufbau des Seitensprosses mit, nicht bei dem des Blattes.

Verfolgen wir nunmehr die Entstehung der jugendlichen Blätter, so sehen wir in der Tat, wie schon Haberlandtfand, denBlattnerven aus einer Periblemzelle hervorgehen.

Es mag hier kurz daran erinnert werden, daß bei dem erwachsenen Blatt, abgesehen vom Mittelnerven, die Spreite nur aus zwei dem Dermatogen entstammenden Zellschichten besteht.

An tangenitalen Längsschnitten, welche die herablaufenden Reihen des Periblems getroffen haben, findet man günstigenfalls die Initialen des Blattnerven als einzelne, sich durch Plasmareichtum und GröBe auszeichnende Zellen; meist sind sie aber schon 
durch eine Wand geteilt (Fig. 4). Die weitere Aufteilung erfolgt durchaus verschieden, in einem Blatt so, im anderen anders.

Die Initialzelle teilt sich entweder durch eine tangentiale oder durch eine radiale Wand, und die Teilstücke bilden, in die Höhe und Breite wachsend, einen Buckel. Im weiteren Verlauf des Wachstums

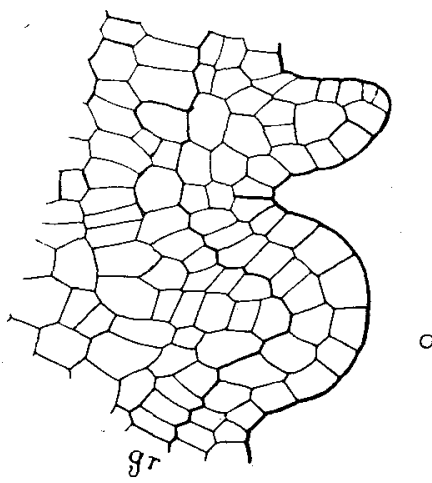

Fig. 3. Längsschnitt durch einen Seitensproß des in Fig. 2 dargestellten Scheitels von Elodea densa. Vergr. ca. 260.

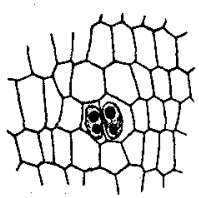

Fig. 4. Tangentialer Längsschnitt eines Scheitels von Elodia canadensis mit der Anlage eines Blattnerven in der Periblemschicht. Vergr. ca. 200.

vermehren sich mit der Zahl der Zellen naturgemäß die Möglichkeiten der Wandbildung. Auch die in den benachbarten Reihen liegenden Zellen beteiligen sich zunächst am Wachstum, bleiben jedoch hinter der mittleren Hauptinitiale zurïck und stellen ihr Wachstum bald gänzlich ein. So kommt es, daß man auf einer Serie von tangentialen Längsschnitten,
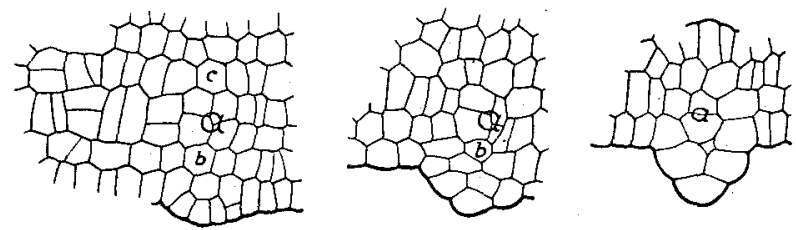

Tig. 5, 1-3. Tangentiale Längsschnitte durch einen Scheitel von Elodea canadensis, in welchem ein junges Blatt in verschiedenen Höhen quergeschnitten ist; $A a$ die Zellen, aus denen der Blattnerv hervorgeht. Vergr. ca. 200.

welche ein junges Blatt quer treffen, von außen nach innen fortschreitend, zuerst die der „Hauptinitiale“ ( $a$ in Fig. 5) entstammende Zellreihe schneidet, und dann erst die zum Teil mit emporgewachsenen Zellen $b$ und $c$ (Fig. 5) findet. Den ersten tangential oder radial verlaufenden Teilungswänden der. Initialzelle folgen zu 
diesen rechtwinklige Wände, so daß die ursprüngliche Zelle in drei bis. vier Zellen zerlegt wird.

Ein junges Blatt hat auf dem medianen Längsschnitt in der Regel ein Aussehen, wie es die Fig. 6 illustriert. Die den Blattnerven bildende Periblemzelle ist in diesem Falle zuerst durch die Perikline 1 in eine innere und eine äußere Zelle zerlegt worden. Die letztere ist nach dem Auswachsen ebenfalls periklin durch Wand 2 geteilt worden. Dann ist in der mittleren Reihe die Wand 3 aufgetreten. Die in Fig. 6 mit 1-3 bezeichneten Wände findet man in Fig. 7 mit Leichtigkeit wieder, und es ist ohne weiteres ersichtlich, wie sich die in Fig. 6 aus der einen Periblemzelle hervorgegangenen Deszendenten weiter geteilt haben.

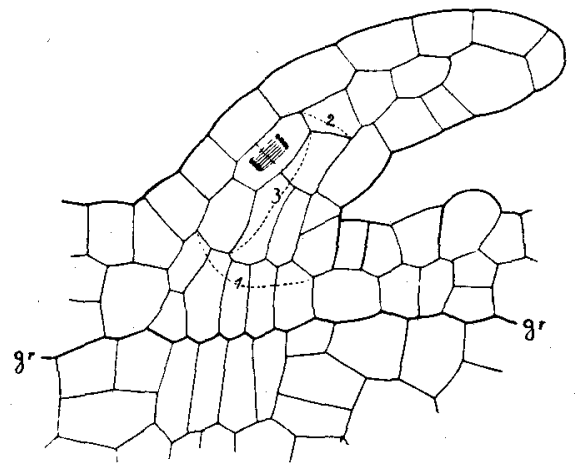

Fig. 7 .

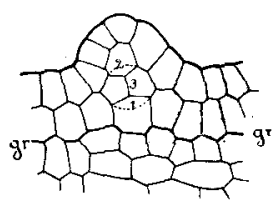

Fig. 6.

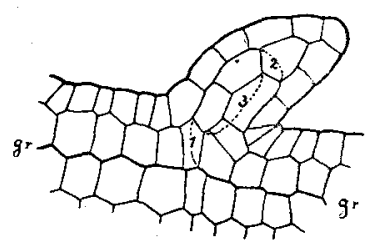

Fig. 8.

Fig. 6. Längsschnitt durch eine junge Blattanlage von Elodea canadensis. Vergr. ca. 200.

Fig. 7. Längsschnitt durch ein älteres Blatt von Elodea densa. Vergr. ca. 300. Fig. 8. Längsschnitt durch ein älteres Blatt von Elodea canadensis. Vergr. ca. 200.

Etwas schwerer ist die Fig. 8 zu verstehen. Hier sind die Wände mutmaßlich in der Folge der beigeschriebenen Zahlen aufgetreten. In solchen Fällen sieht der ältere Zustand so aus, als sei der Blattnerv mit zweischneidiger Scheitelzelle gewachsen.

Verfolgen wir die Anlage des Blattnerven auf einer Serie von Querschnitten durch ein junges Blatt, so sehen wir, unter Vernachlässigung sekundär auftretender Teilwände, eine ähnliche Zellanordnung auf allen Querschnitten wiederkehren. Ein Beispiel dafür gibt die Blattquerschnittserie in Fig. 9.

Während das jugendliche Blatt sich zunächst an seinem apikalen Ende verlängert, haben die älteren Blätter ein ausgesprochen basales. Wachstum. Auf Längsschnitten zeigt die untere Hälfte älterer Blätter 
eine reiche Zahl von Zellteilungen und kleine Zellen, dagegen die obere verhältnismäßig große Zellen.

Die unter der Ansatzstelle des jungen Blattes liegenden Zellen des Periblems und des Pleroms erfahren eine Reihe von antiklinen Teilungen, durch welche sie zu Prokambiumzellen für die Blattspurstränge werden, die den Anschluß des Blattnerven an das Bündel des Stammes vermitteln (Fig. 7).

Das Ergebnis der Untersuchung wäre somit dahin zusammenzufassen, daß im Scheitel von Elodea eine Sonderung in drei Histogene

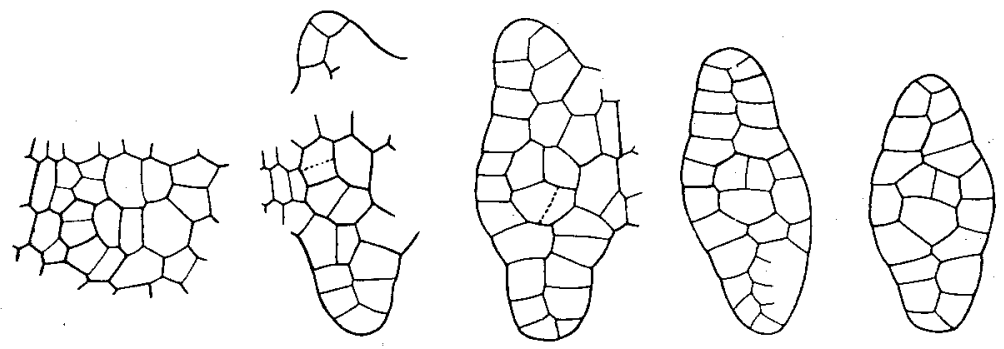

Fig. 9. Querschnittsserien durch junge Blätter von Elodea canadensis. Vergr. ca. 200.

besteht, deren jedes mit einer oder mehreren Initialen wächst. Das Blatt entsteht mit Ausnahme des Blattnerven, der einer Zelle des Periblems entstammt, ausschließlich aus dem Dermatogen.

\section{Hippuris vulgaris.}

Auch Hippuris vulgaris ist in bezug auf den Bau seines Scheitels bereits mehrfach untersucht worden, zuerst von Sanio und de Bary, später von Kny (1878), Schoute (1903) und Kniep (1904). Der schlanke Stammscheitel besitzt ein einschichtiges Dermatogen und drei bis fünf Mantellagen von Periblemzellen, die das Plerom kappenförmig umgeben und am Scheitel lückenlos aneinander schließen. Die Blätter stehen in etwa acht- bis zwölfzähligen Wirteln, alternieren, sind verhältnismäßig klein und einfach gebaut und bieten ein relativ günstiges Untersuchungsobjekt.

Daß Plerom und Periblem immer getrennte Initialen haben, möchte ich zwar nicht mit absoluter Gewißheit behaupten, doch aber für wahrscheinlich halten. An den meisten Präparaten ist die Sonderung unverkennbar (vgl. Fig. 10). Bisweilen tritt allerdings die Grenze in den Schnitten nicht deutlich hervor, aber diese Tatsache kann sehr wohl in ungünstiger Schnittführung ihre Erklärung finden. 
Kny gibt an, daß er in der innersten, eventuell auch in der zweitinnersten Periblemlage tangentiale Teilungen habe auftreten sehen und schließt daraus, daß das Periblem an das Plerom Schichten abgebe, daß also keine streng geschiedenen Histogene vorhanden seien. Dieser SchluB scheint mir nicht gerechtfertigt zu sein.

Schoute dagegen vertritt die Ansicht, daß aus dem Plerom die Endodermis und die anstoßende innerste Rindenschicht hervorgehe.

Tangentiale Teilungen im Periblem treten zwar auf und führen zu einer Verdoppelung der einzelligen Periblemlagen auf Quer- und Längsschnitten, bleiben aber, wie wir sehen werden, als aus einzelnen Periblemzellen hervorgehende Zellkomplexe kenntlich, und es ist klar,

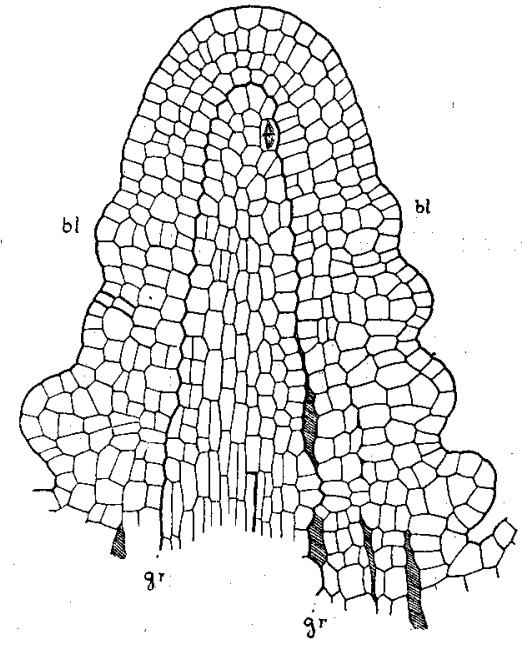

Fig. 10. Medianer Längsschnitt durch einen Scheitel von Hippuris vulgaris. Vergr. ca. 200. daB sie sich nicht am Aufbau des Zentralzylinders beteiligen. Es besteht vielmehr die strenge Sonderung der Histogene, die schon Sanio und de Bary beschreiben, und von deren Vorhandensein sich in neuer Zeit Kniep wieder überzeugte.

Betrachten wir den in Fig. 10 dargestellten medianen Längsschnitt eines Hippurisscheitels, so sehen wir, daß der Pleromkörper in diesem Falle von nur drei Periblemzellagen umgeben wird. Das Verhalten dieser Schichten in bezug auf ihr Teilungsvermögen ist ungleich. Während wir in den beiden inneren Mantellagen - besonders auf der rechten Seite des Schnittes - neben queren viele tangentiale Teilungen beobachten, deren Zahl sich in den einzelnen ursprünglichen Periblemzellen mit steigender Entfernung vom Scheitel vermehrt, legt sich die subepidermale Schicht einzellreihig im ganzen Verlauf des Schnittes dariuber.

Die ersten Wände, die in der äußersten Periblemschicht auftreten, werden bei der Anlage junger Blätter gebildet, deren jüngste Stadien wir auf Längsschnitten dicht unter dem Scheitel als schwache Vorwölbungen der Epidermis mit einem darunter befindlichen, durch tangentiale Teilung entstandenen Zellenpaar beobachten (Fig. $10 \mathrm{bl}$ ). 
Suchen wir jetzt auf Querschnitten dieses Stadium der Blattentwicklung wiederzufinden und verfolgen wir $\mathrm{zu}$ diesem Zweck eine Reihe von Querschnittsbildern einer Schnittserie. Beginnen wir mit Schnitt Nr. 4 (Fig. 11) - mit Nr. 4 bezeichne ich den vierten Schnitt der Serie, der Pleromgewebe enthält —, so erkennen wir, daß das Plerom aus einem einzellschichtigen Ring und einer zentralen Zelle besteht. Diese Zellen entstehen offenbar so, daß eine an der Pleromspitze liegende Initiale gleichsam als vielseitige Scheitelzelle nach den Seiten und nach unten Elemente abschneidet.

Da das Periblem auf tangentialen Schnitten durch die einzelnen Scheitelkappen nie ähnliche Bilder zeigt wie das Plerom, so muß ich annehmen, daß die Bildungsweise beider Histogene verschieden ist und die Histogene selbst von Anfang an voneinander unabhängig sind. $\mathrm{Zu}$
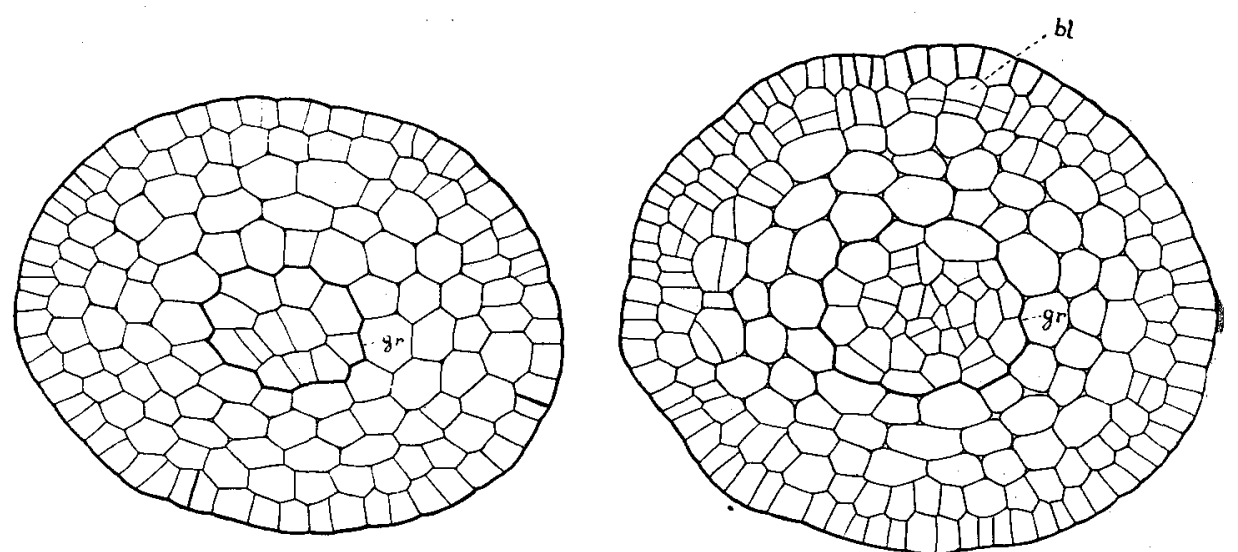

Fig. 11 und 12. Zwei Querschnitte durch den Stammscheitel von Hippuris vulgaris, einer Schnittserie entnommen. Vergr. ca. 300.

vollkommener Klarheit hierüber konnte ich nicht gelangen, trotzdem ich eine große Anzahl von Objekten untersuchte.

Um den Pleromkörper ziehen sich vier Zellkreise (Fig. 11), die Querschnitte der vier Mantellagen des Periblems. Ihre äußerste wird durch das einschichtige Dermatogen umschlossen. In Fig. 11 haben die Periblemzellen noch in allen vier Kreisen die gleiche Größe, aber in der Innigkeit des Verbandes der Zellen untereinander ist schon ein Unter-. schied zu bemerken.

Während die Zellen der subepidermalen Schicht eng zusammenschließen und radial gestreckt erscheinen, treten an den Kanten der Periblemzellen der drei inneren Kreise bereits kleine Interzellulärräume auf, mit anderen Worten, die Zellen zeigen das Bestreben sich abzurunden. 
Schnitt Nr. 5 bot nichts Neues, dagegen waren in Schnitt Nr. 6 die Unterschiede zwischen den Zellen der verschiedenen Periblemschichten auffälliger geworden. Die Zellen der inneren Periblemringe waren zunächst gewachsen, ohne sich zu teilen, während sich im äußersten Periblemring zahlreiche radiale Wände einschoben. Gleichzeitig war in der subepidermalen Sehicht die erste tangenitale Zellteilung aufgetreten. Es war hier die erste Blattanlage am obersten Knoten getroffen.

Der folgende Schnitt Nr. 7 zeigte in der äußersten Periblemlage keinerlei tangenitale Wände, fiel also in ein Internodium.

Dagegen traten in Schnitt Nr. 8 am zweiten Knoten schon mehrere tangenitale Teilwände auf. Die Differenz zwischen den Zellgrößen des ersten und des zweiten bis vierten Periblemkreises war noch bedeutender geworden und das Plerom hatte an Stärke zugenommen.

In Schnitt Nr. 9 waren in der äußersten Periblemschicht nur zwei tangentiale Wände zu finden, die subepidermalen Zellen schienen infolge radialer Teilungen gestreckter.

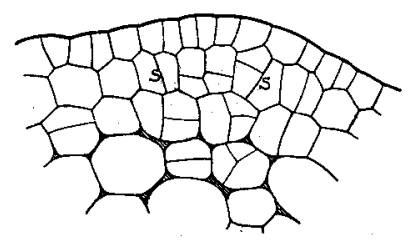

Fig. 13. Teil eines Stammquerschnittes von Hippuris vulgaris mit den ersten Teilungen in der äußersten Periblemschicht. Vergr. ca. 300.

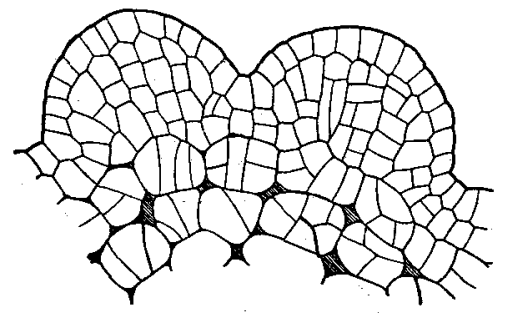

Fig. 14. Ältere Blattanlagen von Hippuris vulgaris aus einem Scheitelquerschnitt. Vergr. ca. 260.

Der nächste Schnitt Nr. 10 (Fig. 12) hatte den dritten Knoten getroffen. Die Größenzunahme der Interzellularräume ist unverkennbar. In der zweiten Periblemschicht sind einige Teilwände von regelloser Orientierung aufgetreten, und die äußerste weist zahlreiche tangentiale Wandbildungen auf. Betrachtet man die Lage der tangential geteilten Zellen zueinander, so findet man sie zu Gruppen vereint an vier Stellen, je zwei oder drei zusammen.

Die Bedeutung dieser Gruppierung ist nicht schwer zu erraten. Jede Gruppe entspricht einer Blattanlage. Ältere Entwicklungsstadien lassen darüber keinen $Z$ weifel. In Fig. 13 hat sich jede der drei zu einer jungen Blattanlage gehörenden Zellen der ersteren Periblemschicht bereits einmal oder zweimal geteilt, die mittlere Zelle zuerst radial, 
ihre beiden Deszendenten tangential. Die rechts und links davon liegenden Zellen haben jedoch als erste Wand je eine schief orientierte $\left(s, s^{*}\right)$ eingeschoben, auf welche in einem Falle (Fig. 13) wieder eine Querwand folgt.

Der weitere Verlauf der Entwicklung geht aus Fig. 14 hervor. Der Schnitt, nach dem sie entworfen ist, ensstammt derselben Serie, wie die ersten Querschnitte. Das junge Blatt hat sich gestreckt und aus dem mittleren Zellkomplex ist dureh Teilung der Zellen ein Zellstrang hervorgegangen, welcher das Prokambium des späteren Blattbündels liefert. Aus den Nachbarzellen rechts und links, die wir sich zuerst schief teilen sahen, geht dagegen durch abwechselnd perikline und antikline Wandbildung das Mesophyll der seitlichen Teile der Blattspreite hervor.

Noch in diesem vorgeschrittenen Stadium der Entwicklung ist die Grenze zwischen der ersten und der zweiten Periblemschicht deutlich zu erkennen. Die Zellen der drei inneren Periblemlagen sind gewachsen und haben mehrfache Teilungen erfahren. Die durch Teilung aus einer Zelle entstandenen Tochterzellen sind zu je einer scharf begrenzten Gruppe vereinigt. Die Interzellularräume lassen schon die Anordnung der späteren Luftgangkreise erkennen. Nie beobachtet man einen Interzellularspalt unter der Anlage eines Blattbündels. An dieser Stelle bleibt die Verbindung mit dem leitenden Strange des Pleroms gewahrt.

Zur Beobachtung der einzelnen Blattentwicklungsstadien auf Längsschnitten sind nur median geführte Schnitte brauchbar. Zuerst erfolgt, wie schon erwähnt wurde, in den dem Periblem angehörenden Initialzellen eines jungen Blattes die Anlage einer tangentialen Wand. Auf dem Scheitellängsschnitt in Fig. 10 befinden sich mehrere solcher Stadien (Fig. 10bl). Die zuerst quergeteilte Periblemzelle stellt, wie wir sehen werden, die Initialzelle des Blattbündels dar.

Die beiden Tochterzellen wachsen und teilen sich abermals durch Querwände, so daß eine Zellreihe entsteht, die aus der ersten Periblemschicht.gleichsam vorgestreckt wird und das Dermatogen vor sich herschiebt. Der in Fig. 15 dargestellte Schnitt gibt dafür eịn Beispiel.

Mit der Anlage des Blattnerven schieben sich die oben und unten anstoßenden Periblemzellen ebenfalls vor, wenn auch schwächer. Auch sie erfahren reiche Querteilungen und bilden die obere und untere Mesophyllschicht des Blattes (Fig. 16).

In der" mittleren Zellreihe treten, sobald das junge Blatt eine gewisse Größe erreicht hat, zahlreiche Längsteilungen auf, welche die ur- 
sprünglich mehr oder weniger kubischen Zellen in gestreckte Prokambiumzellen des Blattbündels umwandeln.

Fig. 17 zeigt dieses Stadium an einem älteren Blatt.

Die Mitte wird von dem meristematischen Blattbündel eingenommen, in dessen unterem Teil die Bildung von Prokambiumzellen bereits vorgeschritten ist. Die Zellen sind gestreckt und ihre Kerne länglich. Weiter gegen die Blattspitze hin sind noch alle Übergangsstadien zu Zellen der primär angelegten Zellreihe zu finden. Auf der dorsalen und ventralen Seite sieht man diejenigen Zellreihen des Mesophylls, welche aus den anderen, an der Blattbildung beteiligten Zellreihen der äußersten Periblemschicht in das Blatt hineinbiegen.

Der Blattnerv läßt sich an diesem Schnitte nicht bis zur äuBersten Spitze des Blattes verfolgen, wie nach Fig. 16 zu erwarten wäre, da der Schnitt das Blatt nicht genau median trifft, sondern durch die mehr seitlich gelegenen Teile des Mesophylls geht.

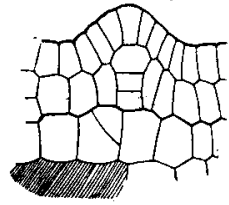

Fig. 15.

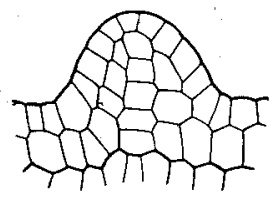

Fig. 16.

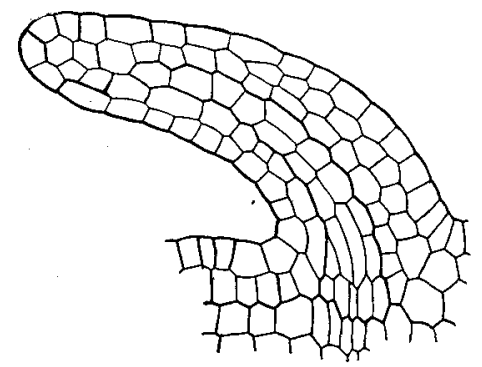

Fig. 17.

Fig. 15 u. 16. Blattanlagen von Hippuris vulgaris im Lăngsschnitt. Vergr. ca. 300. Fig. 17. Medianer Längsschnitt durch ein junges Blatt von Hippuris vulgaris.

Vergr. ca. 300 .

In der Fläche findet die Verbreiterung der Mesophyllplatten durch perikline und antikline Teilungen statt. Es sei hier nochmals auf Fig. 14 verwiesen.

Das Ergebnis der Untersuchung ließe sich somit dahin zusammenfassen, daß bei Hippuris im Scheitel drei getrennte Histogene vorhanden sind, wie schon früher Sanio und de Bary annahmen und in neuerer Zeit Kniep bestätigte. Die Epidermis des Blattes geht aus dem Dermatogen, das gesamte Mesophyll und das Blattbündel aus der äußersten Periblemlage hervor.

Die ersten Entwicklungsstadien der Blätter von Hippuris vulgaris zeigen eine auffallende Ähnlichkeit mit denen der Blätter von Cerato- 
phyllum demersum, die Haberlandt untersucht hat. Man vergleiche z. B. meine Fig. 16 mit Haberlandts Fig. 3 auf Taf. V.

\section{Galium rubioides.}

Galium rubioides gehört zu denjenigen Galiumarten, bei denen durch das ,Verwachsen“ je zweier Nebenblätter aus einem ursprünglich scheinbar sechszähligen Wirtel ein scheinbar vierzähliger wird. Da die Stellung der Blätter die dekussierte ist, so ist man also auf Längsschnitten nicht ohne weiteres über die Natur einer jungen ,Blattanlage“"im klaren. Das Vorkommen von Achselsprossen allein läßt entscheiden, ob man es in dem gegebenen Falle mit einem Blatt oder mit einem Nebenblatt zu tun hat. Sind auf einem Längsschnitt einige Blätter mit Achselsprossen getroffen, so läßt sich durch einfaches Abzählen feststellen, welche Anlagen Blattanlagen und welche Nebenblattanlagen sind.

Der Längsschnitt in Fig. 18 gibt uns Aufschluß über die Verteilung der Histogene.

Auf das einschichtige Dermatogen folgt das ursprünglich gleichfalls einschichtige Periblem. Aber schon wenige Zellen vom Scheitel entfernt treten in ihm tangentiale Teilungen auf, welche es mehrschichtig werden lassen. Die Mitte des Schnittes wird vom Plerom eingenommen.

Über Form, Zahl und Art der Teilungen der Scheitelinitialzellen ließ

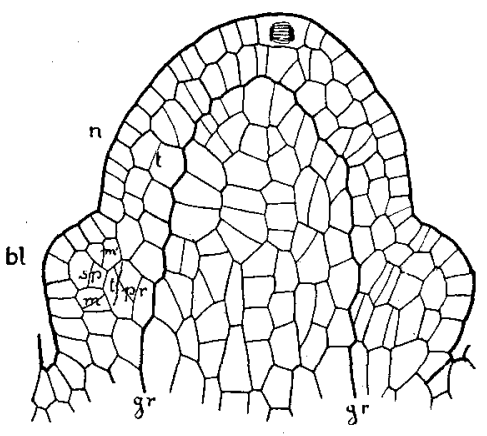

Fig. 18. Medianer Scheitellängsschnitt von Galium rubioides. Vergr. ca. 260. sich nichts feststellen, doch scheinen alle drei Histogene mit getrennten Initialen zu wachsen. Fertigt man eine Serie sehr dünner Querschnitte der obersten Scheitelregion an — ich schnitt $4 \mu$ dick - , so ergeben sich für Dermatogen, Periblem und Plerom Zellnetze, die sich in keiner Weise in genetischen Zusammenhang bringen lassen.

Kehren wir zur Betrachtung unseres Längssehnittes in Fig. 18 zurück. Das Periblem ist unterhalb des Scheitels durch tangentiale Teilungen zweischichtig geworden und bildet bei $b l$ unter reichen Zellteilungen mit dem Dermatogen zusammen eine junge Blattanlage. Die Zellgruppe $m, m^{\mathbf{1}}, s p, p r$ ist zweifellos aus einer primären Periblemzelle hervorgegangen. Die zuerst eingeschobene Wand dürfte $t$ sein, welche der tangentialen Wand - $t$ - bei $n$ entspricht, womit in diesem Falle die Anlage eines Nebenblattes eingeleitet wird. Von den so entstandenen 
beiden Zellen wird die äußere zur eigentlichen Initialzelle für das Mesophyll und das Leitbündelgewebe des neuen Blattes. Auf die Wand $t$ setzen sich zwei radiale Wände, die die äußere Zelle in $m, s p$ und $m^{6}$ zerlegen. In dieser neu entstandenen Gruppe ist die mittlere Zelle $s p$ an der Bildung des Blattbündels beteiligt, während die beiden äußeren Zellen $m$ und $m^{\prime}$ Mesophyll liefern.

In allen drei Zellen $m, s p$ und $m^{c}$ sind bereits die für sie charakteristischen Teilungen aufgetreten. In $s p$ ist eine tangentiale Wand eingeschoben, und die Tochterzellen beginnen sich vorzustrecken, dagegen zeigen $m$ und $m^{r}$ schiefgestellte Wände. Aus den Zellen der Gruppe $p r$

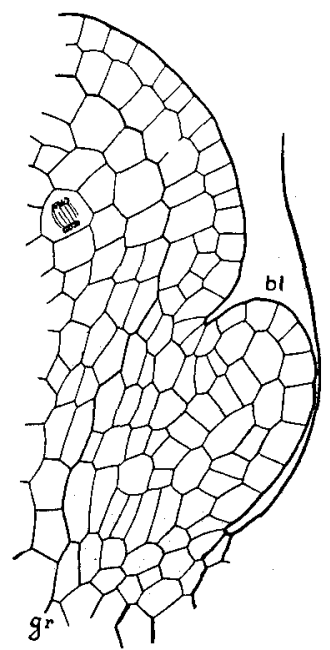

Fig. 19.

bilden sich Prokambiumzellen, die später die Verbindung zwischen dem Blattbündel und dem zugehörigen Blattspurstrange herstellen.

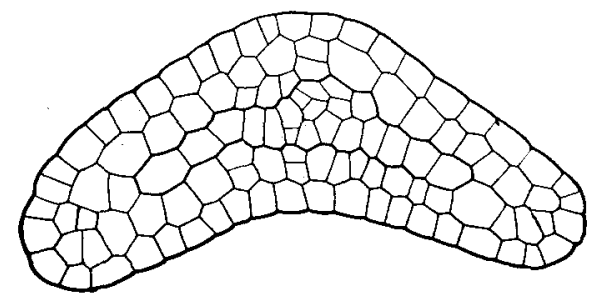

Fig. 20.

Fig. 19. Teil eines Scheitellängsschnittes von Galium rubioides. Vergr. ca. 300 .

Fig. 20. Querschnitt durch ein junges Blatt von Galium rubioides. Vergr. ca. 200.

An älteren Stadien läßt sich das Fortschreiten der Entwicklung in diesem Sinne beobachten.

Die mit $s p$ bezeichnete Zelle teilt sich mehrmals tangential und die an der Bildung des Mesophylls beteiligten Zellen $m$ und $m^{4}$ folgen der Vorstreckung durch Einschiebung antikliner Wände. In der folgenden Figur, Fig. 19, einem Scheitellängsschnitt mit einer älteren Blattanlage, sind die aus den Zellen $m$, sp und $m^{\prime}$ hervorgegangenen Zellgruppen unschwer wiederzuerkennen. In der von $m$ abstammenden Zellreihe sind bereits perikline Wände aufgetreten.

Die Füllung des jungen Blattes besteht ${ }^{1}$ ) also zuerst aus drei

1) Unter Blattfüllung verstehe ich das gesamte Mesophyll des Blattes samt den GefäBbündeln. Die Epidermis, wie überhaupt alle aus dem Dermatogen hervorgehenden Zellschichten (z. B. Wassergewebe), gehören nicht zur Blattfüllung. 
Zellschichten, einer mittleren, aus welcher sich die Blattbündel differenzieren, und einer oberen und einer unteren, die Mesophyll liefern.

Eine Bestätigung dieses Befundes geben uns Querschnitte durch eine Reihe von Blättern verschiedenen Alters.

Das noch ziemlich junge, in Fig. 20 dargestellte Blatt läßt die auf dem Längsschnitt sichtbaren Schichten gut erkennen. Das Dermatogen ist durchgängig einschichtig. In der zweiten Zellage sind nur bei $r$ auf der oberen und unteren Blattseite nahe der medianen einige Periklinen aufgetreten. Aus der mittleren Schicht differenziert sich bereits die Anlage des medianen Blattbündels heraus.

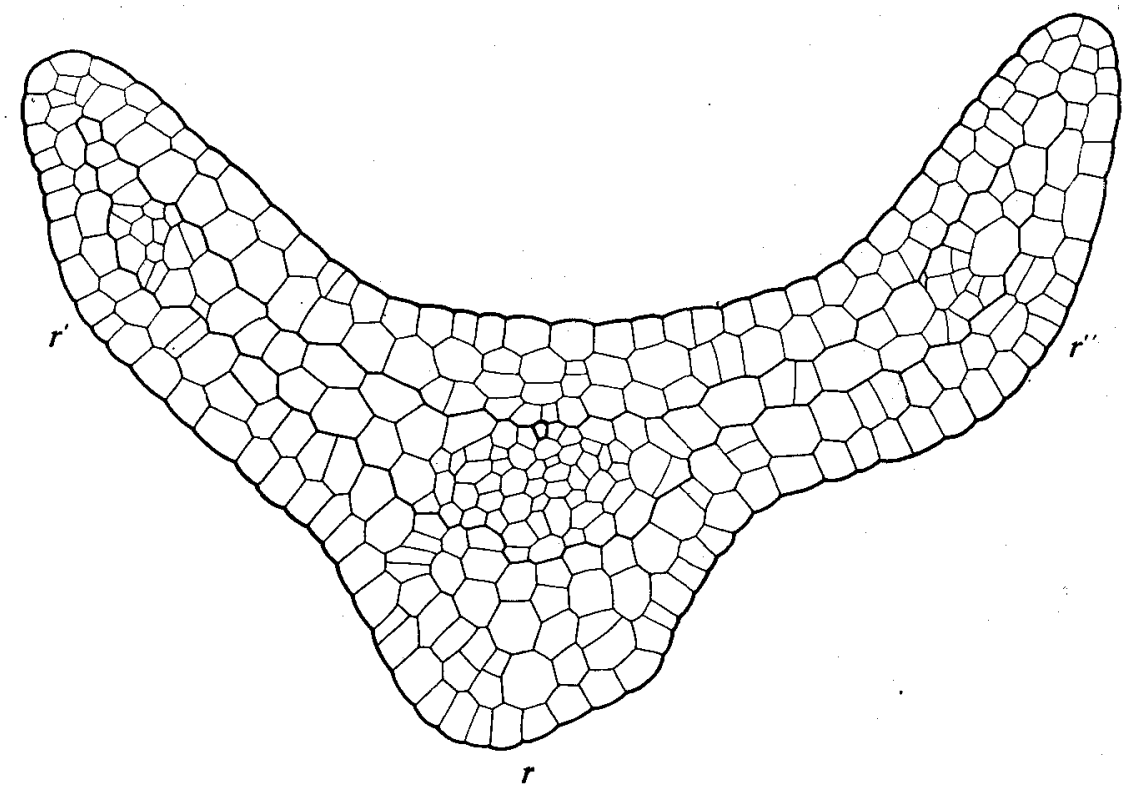

Fig. 21. Querschnitt durch ein etwas älteres Blatt von Galium rubioides. Vergr. ca. 200 .

Die unter dem mittleren Zellstrang der zweiten Zellschicht (von unten gezählt) auftretenden Teilungen sind die ersten Anlagen der später stark vorspringenden Mittelrippe. An den Blattkanten schließen sich die zweite Schicht der Blattoberseite und der Blattunterseite zu einem breiten Randstreifen zusammen.

Auch an älteren Blättern bleiben die Schichtgrenzen deutlich erhalten. Die Prokambiumbildung des mittleren Gefäßbündels schreitet vor und etwas später bilden sich gleichfalls aus der mittleren Schicht heraus die beiden seitlichen Blattnerven. 
In diesem Stadium befindet sich das Blatt, dessen Querschnitt in Fig. 21 abgebildet ist. Über der nach der Blattunterseite vorspringenden Rippe hat sich das Gefäßbündel schon zum Teil differenziert, die Blattrippe ist durch radiales Wachstum der Zellen der zweiten Schicht (von unten gezählt) an dieser Stelle mächtig vorgewölbt. Die bei $r^{\star}$ und $r^{\prime \prime}$ liegenden geteilten Zellen der mittleren Zellreihe sind die Anlagen der seitlichen Blattnerven. Auch unter ihnen findet starke Rippenbildung statt, deren Beginn sich durch perikline Teilungen der unteren Zellen bei $r^{\prime}$ und $r^{\prime \prime}$ kundgibt.

Die später auftretenden Queranastomosen der drei Blattnerven lassen sich auf Blattquerschnitten nicht gut verfolgen, da die kleinen

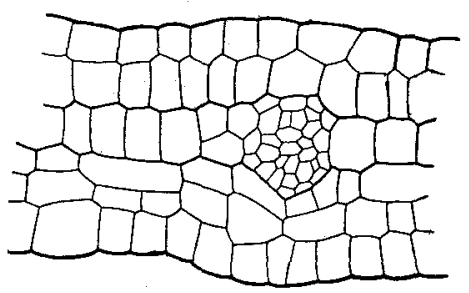

Fig. 22 .

Fig. 22 Längsschnitt durch ein älteres Blatt von Galium rubioides, das eine Gefäßbündelanastomose quergeschnitten zeigt. Vergr. ca. 200 .

Fig. 23. Längsschnitt durch ein Blatt von Galium rubioides mit der Anlage eines Achselsprosses (a). Vergr. ca. 260.

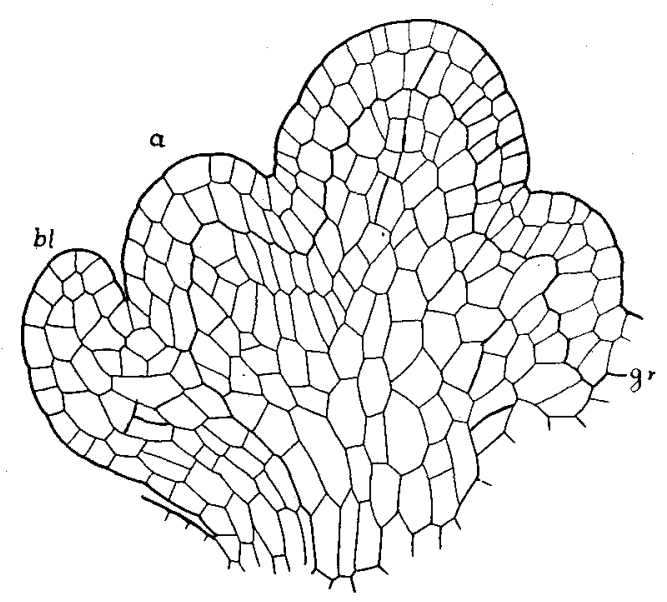

Fig. 23.

Zellen meist kein klares Bild geben. Trifft man dagegen Queranastomosen eines älteren Blattes auf dem Blattlängsschnitt günstig quer, so sieht man, daß sie in der mittleren Zellschicht entstehen (Fig. 22). Die obere Zellschicht der Blattfüllung ist meist noch ungeteilt. Ihre Zellen sind im Begriff, infolge antikliner Teilung und Streckung palisadenähnlich zu werden. Aus der unteren Schicht sind dagegen zwei geworden. Aus den entstandenen gestreckten Zellen bildet sich das Schwammparenchym. Wir sehen also, daß das Blatt, abgesehen von der Epidermis, in allen seinen Teilen aus dem zweiten Histogen, dem Periblem, entsteht, und zwar aus dessen äußerer Schicht. Im Gegensatz dazu ist beim Aufbau der Achselsprosse das Plerom beteiligt. 
Der in Fig. 23 dargestellte Scheitel weist auf seiner linken Seite in der Achsel des Blattes $b l$ einen jungen Seitensproß $a$ auf. Verfolgt man vom Scheitel des Hauptsprosses aus das Periblem, so sieht man es als ungeteilte Schicht in den Sproß $a$ hineinlaufen. An der Bildung des Sprosses $a$ ist aber auch ein vom Plerom ausgehender Zapfen beteiligt, welchen Periblem und Dermatogen kappenförmig umgeben.

Aus diesen Beobachtungen geht mit hinreichender Sicherheit hervor, daß von den seitlichen Ausgliederungen eines Sprosses von Galium rubioides die Blätter aus dem Dermatogen und Periblem entstehen, während an der Bildung der Seitensprosse das Plerom mitbeteiligt ist.

\section{Honckenya peploides.}

Honckenya peploides ist eine weitverbreitete Strandpflanze unserer deutschen Meeresküsten aus der Familie der Alsineen mit kriechendem Rhizom und aufrechtem vierkantigen Stengel, an welchem die dicken, fleischigen und elliptischen Blätter dekussiert angeordnet sind. Die Blüten stehen einzeln in den Blattachseln und werden schon frühzeitig angelegt. Sie machen die Verhältnisse im Scheitel, welcher kurz und gedrungen ist, unübersichtlich. Es war schwierig, Scheitel zu bekommen, in deren Blattachseln noch keine Blütenanlagen vorhanden waren. Am geeignetsten erwiesen sich zur Untersuchung solche Achselsprosse, die nach der Blütezeit, Ende Juni, entstanden waren.

Trotz der vorgenannten, für die Untersuchung wenig vorteilhaften Eigenschaften bietet Honckenya insofern ein gutes Objekt, als ihre Zellen verhältnismäßig groß sind und das Periblem aus zwei scharf vom Dermatogen und unter sich gesonderten Schichten besteht, die das Plerom am Scheitel kappenförmig umgeben.

Während bei Galium das Periblem, ursprünglich einschichtig, kurz unterhalb des Scheitels aber meist zweischichtig, sich augenscheinlich nur mit seiner äußeren Region am Aufbau des Blattes beteiligt, werden bei Honckenya, wie die Untersuchung lehrte, beide Periblemschichten zur Blattbildung herangezogen.

Am Scheitel von Honckenya sind die Peribleminitialen offenbar in zwei Etagen übereinander angeordnet, und jede der beiden Periblemkappen wächst unabhängig von der anderen.

Das Stadium eines medianen Scheitellängsschnittes, in welchem eine jugendliche Blattanlage getroffen ist, läßt folgendes erkennen. 
Unter der einschichtigen Epidermis (Fig. 24) liegen zwei Schichten Periblem, die sich deutlich vom Plerom abheben. Beide Periblemkappen sind zunächst einschichtig und wachsen durch Einschieben antikliner Wände unabhängig voneinander. Ihre Grenze gegen das Plerom läßt sich bis hinter die ersten Blattanlagen verfolgen.

Wird an einer bestimmten Stelle ein neues Blatt angelegt, so treten sowohl in der ersten wie in der zweiten Periblemschicht tangentiale Wände auf, die beiden Schichten verstärken sich an dieser Stelle, doch überwiegt bald das Wachstum der inneren Periblemlage. Der von der zweiten Periblemschicht gebildete Zapfen vergrößert sich und stülpt sich in die von der ersten Periblemschicht gebildete Kuppe vor. Ein vorgeschritteneres Stadium gibt Fig. 25 wieder. Der von der zweiten

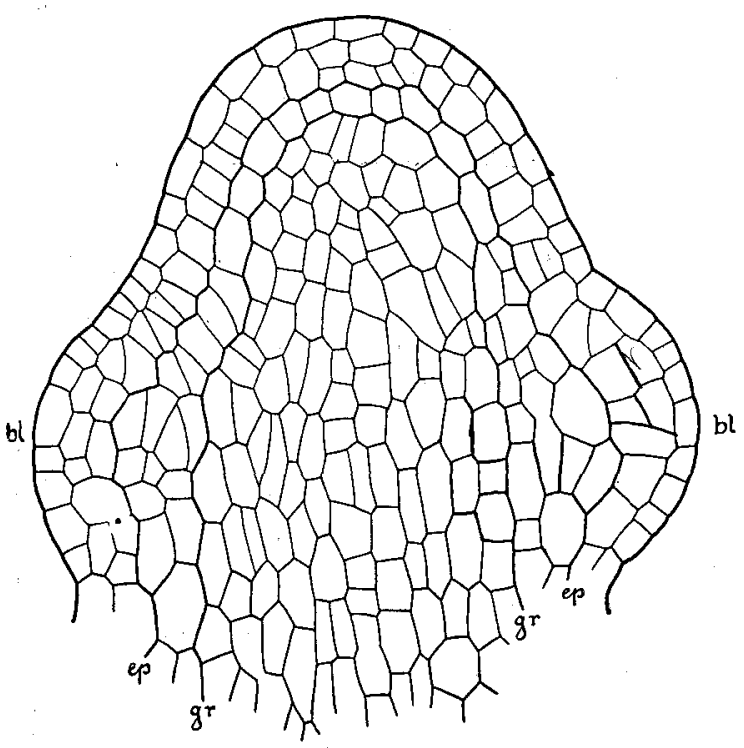

Fig. 24. Scheitellängsschnitt von Honckenya peploides mit jugendlichen Blattanlagen $(b l)$, ep Grenze der ersten Periblemschicht. Vergr. ca. 300.
Periblemschicht gebildete Zappen hat sich vergrößert, und in die von der ersten Periblemschicht gebildete Kuppe vorgestülpt, die Grenze zwischen $p^{\prime}$ und $p^{\prime \prime}$ ist noch sicher zu verfolgen. In den meisten Fällen schneidet man nur eine Blattanlage median, während der opponierte Blattbuckel mehr peripher getroffen wird. Der Grund hierzu ist, abgesehen von Fehlern beim Orientieren der Objekte, darin zu suchen, daß die einzelnen Wirtel in der Knospenlage stets etwas gegeneinander verdreht liegen, so daß bei der Orientierung nach älteren Blättern die der jüngsten zu wünschen übrig läßt. In welchem Maße sich die zweite Periblemschicht an der Blattbildung beteiligt, untersucht man am besten auf einer Längsschnittserie durch ein junges Blatt. Auf allen Bildern findet man den von der zweiten Periblemschicht gebildeten Zapfen wieder, den die äußere Periblemkappe in ziemlich gleichmäßiger Mächtigkeit umgibt. Nie findet eine Beteiligung aus dem Plerom stammender 
Zellelemente statt. Die unter der Blattansatzstelle liegenden Pleromzellen behalten lange ihren meristematischen Charakter, erst wenn das junge Blatt an Größe zugenommen hat, treten im Plerom Längsteilungen auf, wie in Fig. 25. Auch die angrenzenden Zellen der zweiten Periblemschicht zeigen die gleiche Streckung und bilden die Prokambiumzellen, welche den Anschluß des Blattbündels an den Blattspurstrang vermitteln. An noch älteren Blättern wird die Grenze zwischen $p^{4}$ und $p^{\prime \prime}$ sehr schnell undeutlich.

Einem Objekt von gleichem Alter wie der Blattlängsschnitt in Fig. 25 gehört etwa der Querschnitt in Fig. 26 an. Das Präparat entstammt einem tangentialen Scheitellängssehnitt und zeigt das Blatt im Querschnitt an seiner Insertionsstelle. Nur an dieser Stelle besteht bei der starken Aufwärtskrümmung des jungen Blattes die Möglichkeit, ein klares Bild zu erhalten. Die Grenze der beiden Periblemschichten

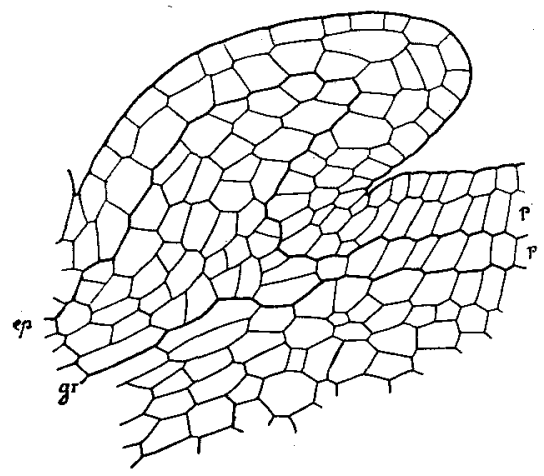

Fig. 25. Medianer Längsschnitt durch ein junges Blatt von Honckenya peploides, ep Grenze der ersten Periblemschicht. Vergr. ca. 300.

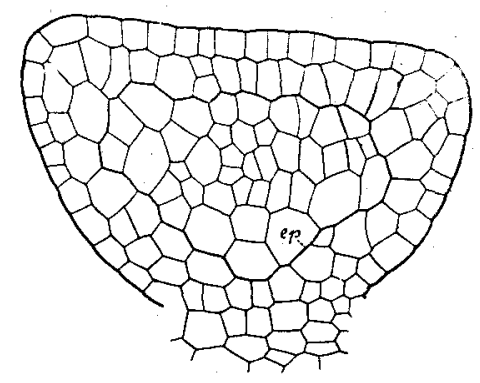

Fig. 26. Blattquerschnitt von Honckenya peploides, geschnitten an der Insertionsstelle des Blattes am Stengel. Vergr. ca. 300 .

ist leicht festzustellen. $P^{\prime}$ ist im allgemeinen einschichtig, nur in den Winkeln des fast dreieckigen Blattes mehrschichtig. Im Innern der zweiten Periblemsehicht $p e^{\prime \prime}$ bildet sich das Prokambium des mittleren Gefäßbündels aus, dem erst später die Anlage zweier seitlicher Bündel folgt.

\section{Schlußbemerkungen.}

Alle von mir untersuchten Pflanzen lassen im Scheitel die Sonderung der primären Histogene im Sinne v. Hansteins erkennen, und es war in jedem Falle möglich, die Grenzen von Dermatogen, Periblem und Plerom mehr oder minder weit am Scheitel herab zu verfolgen. 
Über Anzahl und Teilungsverhältnisse der Scheitelzellen etwas Genaueres zu erfahren, ist mir im Laufe dieser Untersuchung zwar nicht gelungen, die Schwierigkeiten sind offenbar sehr große, immerhin ging mit ziemlicher Sicherheit daraus hervor, daß jedes der drei Histogene besondere Initialen besitzt. Was die Ausgliederung der Blätter anbelangt, so gehen diese, wie wir gesehen haben, ausschlieBlich aus dem Dermatogen und dem Periblem hervor, dessen Schichten in verschiedener Zahl am Aufbau des Blattes beteiligt sein können.

Abgesehen von Elodea, deren Blattnerv sich auf eine Periblemzelle zurückführen läßt, wird die Blattfüllung von mindestens einer Querreihe von Periblemzellen gebildet. Es geht daraus hervor, daß in diesem Falle die Entstehung einer Sektorialchimäre im Sinne Baur's mit sektorial geteiltem Blatt ohne weiteres möglich ist. Da die Scheitelzellen jedes Histogens, wie aus dem Entstehungsmodus der Sektorialchimäre hervorgeht, in Mehrzahl auftreten müssen, so kann die Grenze der verschieden gearteten Deszendenten der Scheitelzellen in der Mitte oder seitlich durch eine Blattanlage laufen. Bei Galium rubioides beteiligen sich z. B. fünf bis sechs nebeneinanderliegende Periblemzellen an der Bildung der Blattfüllung, so daß die Größe eines Sektors ausgiebig variiert werden kann. Maßgebend ist, wieviele der nebeneinanderliegenden, die Blattfüllung bildenden Periblemzellen genetisch sich auf eine oder verschiedene Initialen zurückführen lassen.

Größere Schwierigkeiten macht die Deutung der Periklinalchimären, bei denen verschieden geartete Zellschichten übereinander gebildet werden, so daß sich ihr Scheitel aus verschiedenen übereinander gelagerten Kappen zusammensetzen muß. Beispielsweise könnten die weißbunten Periklinalchimären der Pelargonien in der Weise zustande kommen, daß sich am Aufbau der Blätter mehrere Periblemschichten beteiligen, wie dieses etwa für Honckenya der Fall ist. Besäße die äußere Periblemschicht von Honckenya farblose Chromatophoren, so würde die Pflanze ein ähnliches Bild bieten, wie eine Weißrandpelargonie. Wäre dagegen die zweite Periblemschicht farblos, so erhielten wir eine Periklinalchimäre, welche innen weiß ist, ähnlich den innen weißen Pelargonien. Offenbar verhält sich die Sache auch so. Pelargonium ist zwar in bezug auf seinen Blattbau von mir noch nicht genauer untersucht, doch zeigt schon ein Handschnitt, daß das Periblem sich in zwei oder drei Schichten über den Scheitel hinwegzieht. Beteiligen sich auch hier die verschiedenen Schichten des Periblems am Blattaufbau und sind die Chromatophoren der einzelnen Schichten entweder weiß oder grün, so muß eine Periklinalchimäre entstehen, wie wir sie bei den Pelargonien finden. 
Erinnern wir uns aber der Blattentwicklung von Galium rubioides, dessen Blattfüllung aus einer Querreihe der äußeren Periblemschicht allein hervorgeht, so müßte die Entstehung einer Periklinalchimäre, deren Blätter weißrandig sind, in diesem Falle unmöglich sein, es sei denn, daß die Spaltung von weiß und grün nicht im Scheitel, sondern. bei den ersten Teilungen, die zur Anlage des jugendlichen Blattes führen, erfolgt. Keinesfalls kann eine so regelmäßige Schichtung erfolgen, wie sie die Periklinalchimären aufweisen.

Während das Blatt unter Ausschluß des Pleroms entsteht, haben. wir in zwei Fällen gesehen, daß dieses die Seitensprosse mit aufbaut, indem es zapfenartig in die vorgestülpte Dermatogen- und Periblemkappe hineinwächst. Dieser Modus scheint der normale zu sein. Das. Auftreten rein weißer oder rein grüner Rückschläge bei den Weißrandpelargonien beruht also wohl auf einer durch irgendwelche Störung verursachten anormalen Regeneration. Es muB der Sproß entweder aus den weißen Periblemschichten gebildet werden, oder aus den inneren. grïnen Periblem- oder Pleromschichten. Ob es sich bei dem Auftreten dieser Rückschläge um normale Achselsprosse oder um Adventivbildungen handelt, ist mir nicht bekannt. Wir wissen z. B. aus den Versuchen von Hansen mit Begonia Rex oder den Versuchen Winklers mit Torenia asiatica, daß ein Adventivsproß, der einem normal entstandenen Achselsproß vollkommen gleichwertig ist, allein aus der Epidermis regeneriert werden kann. Ebenso lehren die Rückschläge bei Laburnum Adami zu Cytisus purpureus, daß die Epidermis allein zur Sproßbildung befähigt ist.

Bei Laburnum Adami ${ }^{1}$ ) stimmt das Wachstum der Cytisus pur pureus- und Laburnum vulgare-Komponente offenbar nicht gut zu sammen, daher das häufige Auftreten von Rückschlägen in die ein oder die andere Stammform. Weit besser passen sich die weiße und grün Komponente der Weißrandpelargonien im Wachstum einander an was ja begreiflich ist, da die Komponenten derselben Spezies und Sippe bzw. denselben Individuen angehören; demzufolge treten Rückschläge weit seltener auf. Daß aber auch hier die Anpassung keine vollkommene ist, sieht man in den Fällen, in denen in einem Weißrandpelargonienblatt die grünen inneren Schichten einmal nach außen durchbrechen. Sie scheinen dann aus der weißen Hülle gleichsam hervorzuquellen, nachdem die das stärkere Wachstum der grünen Zellen hemmende weiße Schicht gesprengt ist.

1) Buder, Studien an Laburnum Adami. Zeitschr. f. indukt. Abstammungsehre 1911. 
Genaueres hierüber müßten eine Reihe weiterer eingehender Untersuchungen lehren, mit denen ich mich in der Folge zu befassen gedenke.

Die Arbeit wurde ausgeführt im pflanzenphysiologischen Institut der Universität Berlin; ich spreche Herrn Geheimrat Haberlandt, dessen Leiter, sowie Herrn Professor Claußen für ihre freundliche Unterstützung meinen ergebensten Dank aus.

\section{Zusammenfassung.}

Die Ergebnisse der Arbeit lassen sich in folgende Sätze zusammenfassen:

1. Die Untersuchung erstreckte sich auf fünf Objekte: Elodea canadensis, Elodea densa, Hippuris vulgaris, Galium rubioides und Honckenya peploides.

2. Bei allen fünf Objekten kann man im Scheitel drei Histogene unterscheiden: Dermatogen, Periblem und Plerom, deren jedes mit gesonderten Initialen wächst.

3. Das junge Blatt bildet sich aus dem Dermatogen und dem Periblem, während bei der Bildung der Achselsprosse das Plerom mitbeteiligt ist.

4. Das Periblem ist in der Scheitelkuppe einschichtig bei Elodea und Galium, zweischichtig bei Honckenya, und drei- bis fünfschichtig bei Hippuris.

5. Bei Elodea, Hippuris und Galium läßt sich die Entwicklung des Blattes auf eine Periblemzellschicht zurückführen, während bei Honckenya zwei beteiligt sind.

6. Das Periblem von Galium wird während der Anlage der Blätter in eine äußere und eine innere Schicht zerlegt, von denen sich an der Blattbildung nur die äußere beteiligt.

7. Das Blatt von Elodea besteht, abgesehen von der Mittelrippe, aus zwei Schichten, die dermatogenen Ursprungs sind, während die Rippe dem Periblem entstammt.

8. Die Blätter von Hippuris, Galium und Honckenya sind mehrschichtig. Es differenzieren zwischen dem beiderseitigen Dermatogen sich gleich bei der Anlage eine mittlere Schicht, in welcher die Blattbündel zur Anlage kommen, eine obere und eine untere Schicht, von denen die eine zum oberen assimilierenden Blattgewebe, die andere zum unteren Schwammparenchym wird.

Pflanzenphysiologisches Institut der Universität Berlin-Dahlem, den 26. März 1914. 